\title{
EM TORNO DA APHASIA
}

\author{
POR A. DE ALMEIDA PRADO
}

\author{
"Ce n'est pas mes lumières que je cher- \\ che de repandre, ce sont celles d'autrui". \\ (Gassendi).
}

Nenhum problema neurologico supera em complexidade ao da aphasia. Complicado em sua entrozagem physiologica, o problema da linguagem, desdobrado em seus multiplos aspectos pathologicos, recresce em complexidade. Por isso mesmo seduz os grandes espiritos, aquelles que se não comprazem mais na só observação do facto anatomico material, secco e nú, e pedem aos themas especulativos o assumpto capaz de os levar ao terreno virtual das idéas puras, em que florescem as grandes doutrinas medicas.

$O$ volume sobre a aphasia, assignado pelo nome mundialmente conhecido do Prof. Mingazzini (1) que temos á mão, não encara, entretanto o assumpto só pelo lado abstracto a que nos referimos. Constringindo o thema dentro do porte de um manual destinado a medicos praticos e estudantes de medicina, soube 0 eminente neurologista italiano collocar a pratica ao lado da theoria, a semiotica de par com a doutrina, num justo equilibrio que faz o maior valor do livro.

Partindo do simples para o composto abre o volume com um capitulo sobre o exame clinico dos disturbios da linguagem $\mathrm{em}$ que, depois de expôr succintamente a maneira pela qual se desenvolve na criança paulatinamente o mecanismo da elocução, como a criança aprende a falar e, posteriormente, a reconhecer as lettras e a escrever, num encadeamento perfeito de actos superintendidos por um centro commum hypothetico - o centro idéogeno - que os identifica a todos, delimita o campo da aphasia, bem diversa da anarthria, para em seguida, com exemplos clinicos concretos, tratar do que poderiamos chamar a semiologia da aphasia, dentro de todas suas variantes - aphasia sensorial, motora, amnestica, alexia (incapacidade de reconhecer o valor das lettras ou das palavras escriptas), agraphia (perda da memoria dos symbolos graphicos) - não omittindo as provas e a maneira de por em evidencia todos esses modos de ser do phenomeno.

A questão da aphasia sensorial enseja, em seguida, opportunidade para o autor expor idéas originaes acerca do assumpto. Caracteriza-se essa variedade aphasica pela impossibilidade de entender por via acustica - bem que conservado certo grau de intelligencia e poupada a funcção audictiva — a significação das palavras Henschen, cujas theorias encontram em Mingazzini um fervoroso adepto, distingue duas fórmas principaes na surdez verbal: disturbios de comprehensão dos tons verbaes e disturbios de comprehensão do sentido das palavras, on melhor do sentido da linguagem, entendida

(1) Le Afasie por G. Mingazzini. O presente artigo nāo pretende, ser mais do que realmente é - simples noticia bibliographica do livro em questāo; mas pela extenisāo adquirida e pelo valor das doutrinas que resume merecerá por sem duvida a acolhida da "Revista". 
esta ultima não só no que diz com as palavras, mas no que se refere tambem ás locuções. De maneira eschematica, a percepção consciente da palavra presuppõe a percepçâo inicial dos tons verbaes; depoißs, a percepção das syllabas e das palavras, que constam de uma reunião de diversos tons, e finalmiente, o reconhecimento psychico do conteúdo das palavras, que é, em ultima analyse, o verdadeiro acto de comprehensão vocabular.

Prepostos á effectivação desses tres tempos descrevem-se tres centros distribuidos em escalada no lobo temporal: centro da audicção (giri temporaiis transversi); da percepção dos tons verbaes (dois tercos posteriores do cortex da T-I e de T-2); do sentido da palavra (resto do cortex do lobo e substancia medullar correspondente).

Controvertido assaz é o estudo da aphasia em tudo quanto se liga á existencia de centros condicionados ás varias modalidades da funcção da linguagem (escripta ou fallada). Em torno do centro da palavra na circumvolução de Broca, feriu-se a polemica celebre entre Dejerine e Pierre Marie na qual, de lado a lado os mais serios argumientos foram articulados, sem que ficasse resolvida a pendencia.

Mingazzini assim expõe a sua doutrina: a região de Broca esquerda destina-se a transformar a imagem receptiva verbo-acustica, proveniente de dois respectivos centros (direito e esquerdo) nas imagens correspondentes verbo-motoras. Suspensa a transmissão verbo=acustica pela lesão do centro verbo=acustico esquerdo, ou pelo menos difficultada, receberá, todavia, a referida região os impulsos do centro verbo-acnstico direito, muito escassos, entretanto, relativamente aos que lhe são enviados pelo centro verbo-acustico principal, sito á esquerda. Eis porque não conseguirá, em circumstancias taes, coordenar exactamiente as imagens dos elementos motores da palavra, e esta lhe sahirá tropega, inçada de erros paraphrasicos. Segregado o centro de Broca, quando estejam suspensos tambem os estimulos provindos do centro verbo-acustico đireito, não fica elle, no entanto, votado ao mutismo absoluto, como na verdadeira aphasia motora, e como seria de esperar-se a priori de tal situação. A emissão monosyllabica, bi, ou mesmo trisyllabica, com caracter parephasico, é ainda possivel. Dahi resalta a conclusão de que existem na região de Broca congenitamente preformados, eomo caracteristicos hereditarios, mecanismos mnemonicos engrammas - para a emissão, não das palavras, mas das syllabas - os quaes, para serem despertados a funccionar, não necessitam de outros estimulos, sinão os que promanam de vagas impressões acusticas. Do mesmo modo que a criança não necessita senão da educação motora para ensaiar os primeiros passos, por que tem gravado nos centros rolandicos os engrammas motores, assim, para formar o patrimonio verbal não precisa mais que agglutinar as imagens das syllabas registadas hereditariamente, transformando-a na palavra. O acto da elocução consiste, poịs, em colligar as zonas verbo-acustica e verbo-motora por uma synergia continua. A área verbo=motora permanece sempre o centro da representação motora das syllabas; a os estimulos provindos da área verbo-acustica, e excepcionalmente da verbo-optica, cabem o papel de por em jogo esse mecanismo admirarvel.

Pierre Marie (1) numa conferencia recente "Existe-t-il dans le

(1) Presse Medicale n. 17, 1er Mars, 1922. 
cerveau humain des centres innés ou préformés de langage?" repelle categoricamente a noção de centros natos da palavra quer falada, quer lida, quer escripta, escudado em argumentos entre os quaes avulta o da não existencia de feixes ou fibras condiccionados a transmittirem aos orgams phonadores - lingua, palato, labios - os impulsos partidos do centro. Não se comprehende, com effeito, um centro preformado que não tenha sua via anatotmlica de execução. Ora até hoje, a não ser o feixe hypothetico da palavra de Raymond e Arthaud, que existe só como abstração, não se conhecem fibras que desempenhem essa funıção, além de que os trabalhos anatomicos de Flechsig mostraram que em toda a região considerada hoje como região da aphasia (Gyrus supramarginalis, prega curva, 1.as temporaes) - só existem fỉbras de associação, sem fibras de projecção. Ao conceito dos centros natos substitue Pierre Marie o dos centros adaptados.

Existe, evidentemente, no cerebro humano uma zona, ou um centro si quizermos, cuja alteração determina a aphasia, mas não formado congenitamente, porem simplesmente adaptado funccionalmente ao acto da linguagem, do mesmo modo como a pratica dos esportes, da musica, etc. - procede de outros tantos centros igualmente adaptados á execução desses exercicios.

Traz á balha tambem o exemplo dos surdos mudos e das crianças incapazes te falar, o que contraria litteralmente a noção de um centro preformado, que deveria funccionar automaticamiente como funccionam os outros centros realmente natos taes como os que se relacionam com os outros actos da vida animal: chorar, gritar, mamar, etc.

Essas convicções, quer parecer-nos, não collidem em substancia com as sustentadas por Mingazzini. O que elle sustenta que existam preformados nà região de Broca não são propriamente centros, más mecanismos syllabares (engrammas), assim como na zona motora não existe a graphia dos movimentos complexos, mas do acto muscular desharmonicó, passivel de aperfeiçoamento pelo exercicio e pela educação. Ainda o mesmo exemplo dos surdos-mudos e da críança aproveita á these. Um e outro comquanto incapazes de falar emittem tons, syllabas redobrades, sons paraphasicos, a attestar que as syllabas existem preformadas na área de Broca. A agglutinação dellas, porem, é falha porque o estimulo normal verbo=acustico falta nos surdostmudos.

A aphasia=motora occupa depois a attenção do autor. Definida como a incapacidade de transformação dos componentes das imagens verbo audictivas bem fixadas nas imagens dos movimentos correspondentes da lingua e da bocca necessarios á objectivação verbal correlata, em consequencia da perda da lembrança das imegens motoras da palavra, e assignalados outros caracteres (agrammatismo, disturbios latentes da escripta, perturbações da mimica) peculiares, ou simplesmente frequentes nesta especie aphasica, passa Mingazzini a discutir a séde das lesões apontadas como responsaveis por este typo clinico da aphasia. A proposito da questão, lembra a opinião de Pierre Marie espendida em $1906 \mathrm{em}$ artigos que se tornaram celebres, marcando época $\mathrm{n}_{\mathrm{a}}$ historia da aphasia, que nega ao lobulo de Broca, 3.a circumvolução frontal esquerda, qualquer interferencia nas funcções da linguagem, opinião baseada em duas ordens de factos; uma positiva: a coexistencia de casos typicos de aphasia motora, typo Broca, com integridade da $3 .^{n}$ circumivolução frontal esquerda; outra negativa: a existencia de casos nos quaes 
(individuos dextrimanos) a destruição insulada da porção posterior (pars opercularis) da referida circủmvolução não foi seguida de aphasia motora, o que se verificou, segundo Marie, em $50 \%$ dos casos. Mingazzini não tem por acceitaveis os argumentos supra. Quanto ao primeiro, nota que lesões destructivas da zona em questão, quer á distancia (diaschisis), quer sob a fórma de degeneração lenta que fosse até á destruição dos elementos cellulares da pars opercularis da F. 3 esiquerda, poderiam-lhe ter aboliḍo a funcção, comiquanto a área apparecesse macrosicopicamente integra. Quanto ao segundo, recorda que si $50 \%$ dos individuos escaparam da aphasia com lesões destructivas limitadas exclusivalmente á área em discussão, $50 \%$ restantes tornaram-se aphasicos sob a influencia dessa mesma causa.

|Seria logico, portanto, admittir-se que tanto a lesão da região cerebral arguida, como a da corôa radiada circumjacente, como a do extremo anterior do nucleo lenticular esquerdo, possa produzir o mesmo quadro clinico. A propria circưmvolução de Broca direita não é extranha á producção da aphasia. Mingazzini descreve úm ponto - do qual dá en eschema visão clara - designado por Henschen campo ou zona de Mingazzini (Mingazzinische Feld oder Punkt) em que se dá a convergencia das fibras phasico-motoras direitas e esquerdas, as quaes, por seu turno,, entram em connexão com um segundo feixe de fibras - vias verbo-articulares - originadas da extremidade anterior do putamen, accommodadas estas ultimas vias ao officio de transmittir aos nucleos bulbares o impulso motor correspondente ás imagens verbaes recebidas das fibras phasicomotoras. A funç̧ão da linguagem é, pois, nos primeiros annos de vida, segundo esse modo de vêr, commum aos dois centros de Broca, e pouco a pouco vae ficando adstricta só ao -esquerdo, á medida que o đíreito vae perdendo suas connexões funccionaes (não anatomicas) com os centros verbo acustico e idéogeno esquerdos, permanecenão somente em communicação com o extremo anterior do putamen esquerdo.

Acceitos taes principios, é facil comprehender-se como se possa reclamar a actividade latente verbo-motora da zona de Broca direita, mediante exercicio lento e gradual, quando a zona esquerda esteja funccionalmente abolida.

Os disturbios que dizem respeito com a escripta (disgraphia), leitura (dyslexia), linguagem musical (amusia) e operações arithmeticas de calculos (acalcolia), são estudadas nas paginas seguintes.

Volta-se então o autor ao mecanismo psychico da linguagem, certo um dos mais attrahentes aspectos do problema. Contradicta a Head, cujas doutrinas relegam a um plano inteiramente secundario os chamados centros da linguagem, pois segundo esse illustre neurologista, nenhuma lesão local do cortex cerebral póde interessar a funç̧ão da linguagem isoladamente; interessará certos processos physiologicos que servem de base aos actos complexos da linguagem, mas nunca corresponderá exactamente a determinado grupo de funcções physiologicas.

A perda exclusiva da linguagem motora verificada em individuos jovens, sanissimos miental e physicamente, que apresentaram os symptomas aphasicos em consequencia directa da compressão exercida por fócos hemorrhagicos sobre a zona de Broca e que readquiriram a palavra, uma vez supprimida a acção compressora local, constitue para Mōngazzini demonstração eloquente contra o conceito de Head. Inclina-se mais em acceitar as ideias de Ziehen, 
das quaes dá o substracto. A palavra vive incorporada a patrimonio mental, radicada ás sensações que os attributos dos objectos que ella enuncia sóem provocar nas cellulas cerebraes. Assim a imagem abstracta de uma violeta, por exemplo, só se grava no cerebro integralmente quando identificada á custa das imagens parciaes (visiva, olfactiva, tacto - estereogonostica) que lhe denunciam os attributos relativos ao olfacto, á vista e ao tacto. A palavra só é possivel quando a imagem verbo acustica correspondente á imagem (concreta ou sensorial) da violeta se inscreve na zona de Wiernicke para ser, consecutivamente, projectada através da zona de Broca ao apparelho oro-lingual. Cada uma dessas imagens tem representação ideativa á parte no cortex cerebral, mas estas ligam-se de tal sorte entre si que o estimulo peculiar a ụma dellas (imagem parcial) accorda immediatamente a idéa inscripta nas outras cellulas nervosas correlatas.

A intelligencia do conteúdo psychico dos vocabulos faz-se me-

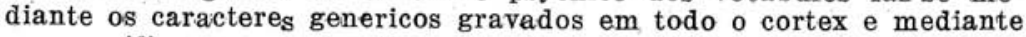
os especificos que concretizam o objecto em questão. Assim á volta do mesmo exemplo - violeta - antes de sie especificar pelos seus caracteres privativos (côr. aroma, forma) suscita o conceito geral de planta, ao qual subsegue o de, muito mais particularizado, violeta. A noção geral de planta, ao ser despertada na mente, suscita simultaneamente numerosas idéas de outras plantas cujas imagens parciaes convibram levemente ao influxo da mesma excitação. 'E', pois, do geral para o particular que as sensações subjectives se individuam nas representações concretas dos objectos aptas para serem traduzidas pela palavra.

$O$ antagonismo entre os apologistas a todo o transe das localizações das funcções da linguagem e os que as negam no sentido psychologico - diz Mingazzini - é mais apparente que real. Porque, si é verdade que para a solida fixação de um engramma verbal concorre toda a córticallidade cerebral, á custa de reevocação das imagens, não o é menos que, com o tempo, a convibração de cada imagem parcial se torna cada vez menos necessaria, especialmente no que toca á reevocação da imagem verbo-acustica, tanto que esta acaba por ter, ao menos em parte, um conteúdo real. Donde a zona verbo acustica assumir a dignidade de um verdadeiro centro intellectual.

E' bem de ver-se que só eschematicamente, só por força do uso e com intuitos didacticos, acceita-se a explicação de factos, de si mesmos tão complicados, reduzidos a simplicidade que os termos imagens motoras, verbo acusticas, graphicas, etc - deixam presuppor. Na realidade o acto da linguagem é muito mais complexo. Para a execução delle concorre uma vasta zona cerebral, o lobo frontal, parte dos lobos occipitaes e temporal, a área de Broca, senão todo o encephalo, como pretende Monakow. Não cabe todavia á zona de Broca só o papel de dispor a musculatura oro-lingual de maneira a se tornar possivel a emissão oral, mas tamberm assenta nella a propriedade de reevocação da resonancia interna da palavra. Não é só o elemento motor que tem ahi a sua séde. Sobreposto a elle ha qualquer cousa mais como provam os dois typos de aphasia cortical e sub-cortical observarveis na pratica.

No primeiro caso, o aphasico motor mostra-se incapez de indicar, pelas provas adequadas, de quantas syllabas se compõem uma determinada palavra: no segundo, não obstante o mutismo absoluto, consegue vencer essa difficuldade. Quer isto dizer que, alem das perturbações motoras, o primeino typo de aphasia encerra qualquer cousa mais - a perda da capacidade de reevocar a resonancia interna verbal - acto inicial, ao qual sobrevêm o da reevocação 
das imagens das syllabas e dos movimentos dos apparelhos oro-glosso-palatino, imprescindiveis á effectivação da palavra falada.

ISeguem-se os capitulos solbre o diagnostico, prognostico e tratamento da aphasia, fechando a monographia o estudo das questões medico legaes relacionadas ao thema.

$\mathrm{Na}$ analyse a que sujeitamos a excellente monographia do eminente neurologista italiano não fizemos mais que lhe resumir as doutrinas contidas nas 125 paginas do volume, procurando ferir os pontos mais importantes do assumpto.

Escripto com clareza e precisão, com abundante contribuição pessoal e, sobretudo, com auctoridade incontrastavel, encerra o livro, quer na parte doutrinaria, quer $\mathrm{n}_{\mathrm{a}}$ clinica, o ensinamento de um neuro-pathologista illustre que é tambem um clinico provecto, um scientista forrado de um medieo na accepção mais alta do termo.

\section{LABORATORIO DE MICROSCOPIA}

E

ANALYSES CLINICAS

\section{Dr. Altino Antunes}

RUA DO CARMO N. 11 Telepho. 2463 (Central) 